\title{
COMPOSTOS BIOATIVOS DO CAFÉ: ATIVIDADE ANTIOXIDANTE IN VITRO DO CAFÉ VERDE E TORRADO ANTES E APÓS A DESCAFEINAÇÃO
}

\author{
Adriene Ribeiro Lima*, Rosemary Gualberto Fonseca Alvarenga Pereira e Sheila Andrade Abrahão \\ Departamento de Ciência dos Alimentos, Universidade Federal de Lavras, 37200-000 Lavras - MG, Brasil \\ Stella Maris da Silveira Duarte e Fernanda Borges de Araújo Paula \\ Departamento de Análises Clínicas, Universidade Federal de Alfenas, Rua Gabriel Monteiro da Silva, 714, 37130-000 Alfenas - \\ MG, Brasil \\ Recebido em26/8/08; aceito em 23/6/09; publicado na web em 13/11/09
}

\begin{abstract}
COFFEE BIOACTIVE COMPOUNDS: IN VITRO ANTIOXIDANT ACTIVITY OF GREEN AND ROASTED COFFEES BEFORE AND AFTER DECAFFEINATION. This study aimed to evaluate the effect of coffee decaffeination with dichloromethane on the in vitro antioxidant activity of this matrix. It were determined the content of total phenolics, chlorogenic acid and caffeine of the coffee samples. The assessment of the antioxidant potential was investigated by DPPH radical scavenging method, reducer power and $\mathrm{Fe}^{2+}$ chelation activity. The process of decaffeination and roasting caused changes in the levels of the compounds investigated. The results show that the decaffeination by the dichloromethane method reduces the in vitro antioxidant potential of coffee.
\end{abstract}

Keywords: coffee; decaffeination; antioxidant activity.

\section{INTRODUÇÃO}

O café é um dos mais valiosos produtos da economia global e sua bebida é uma das mais consumidas no mundo. ${ }^{1} \mathrm{O}$ alto consumo mundial do produto tem estimulado o desenvolvimento de estudos relacionados à atividade biológica do grão e de constituintes do café verde e, especialmente, do café torrado que é utilizado para preparar diferentes tipos de bebidas. Diferentes constituintes do café têm sido sugeridos como potencialmente quimioprotetores em diferentes sistemas químicos e biológicos; a explicação estaria nos numerosos antioxidantes presentes na bebida, como os ácidos clorogênicos, melanoidinas, que são produtos formados na reação de Maillard, e a cafeína.

O café é um alimento singular, pois apesar da degradação parcial dos compostos fenólicos durante a torração, possui atividade antioxidante devido ao desenvolvimento de outros compostos bioativos. ${ }^{2}$ Por definição, a atividade antioxidante é a capacidade de um composto inibir a degradação oxidativa. ${ }^{3}$ Assim, a atividade antioxidante, especialmente a inibição da reação em cadeia, de produtos naturais e alimentos tem sido um parâmetro importante na determinação do valor dietético dos mesmos. ${ }^{4}$

$\mathrm{O}$ interesse pela descoberta de antioxidantes novos e seguros de fontes naturais tem aumentado, principalmente para prevenir o dano oxidativo às células vivas. $\mathrm{O}$ uso de antioxidantes sintéticos tem diminuído devido à suspeita de atividade como promotores de carcinogênese. O papel de antioxidantes dietéticos e seus benefícios para a saúde têm atraído grande atenção nos últimos anos, especialmente aqueles extraídos de plantas. ${ }^{5}$

A busca pelo café sem cafeína tem mobilizado estudiosos do mundo inteiro para atender à demanda crescente de pessoas que querem se livrar dos efeitos colaterais provocados por essa substância estimulante, como a insônia.

O café descafeinado responde por $10 \%$ do consumo mundial de café ${ }^{6}$ e com isso há a necessidade de estudos sobre a composição química do mesmo. A descafeinação é realizada nos grãos verdes inteiros, antes do processo de torração. A maioria dos métodos de descafeinação existentes utiliza solventes para extração da cafeína,

*e-mail: biodri@hotmail.com como o diclorometano, clorofórmio, etanol, acetona, água e outros, sendo o diclorometano o mais utilizado no Brasil. Durante a extração da cafeína há perda de outros componentes ${ }^{7}$ e, embora existam vários estudos sobre a atividade antioxidante do café integral, ${ }^{8-11}$ faltam estudos que avaliem essa atividade na bebida de café descafeinado.

Dessa forma, o presente estudo teve como objetivo analisar o efeito da descafeinação sobre a atividade antioxidante in vitro da bebida de café.

\section{PARTE EXPERIMENTAL}

\section{Material vegetal}

As amostras de café (Coffea arabica L., plantadas no Brasil) foram obtidas através da Indústria Cocam, localizada em CatanduvaSP e foram analisadas antes e após o processo de descafeinação com diclorometano.

\section{Preparo da amostra}

Amostras de cafés (500 g) foram torradas em torrador de laboratório (Probatino - modelo Leogap, Brasil) com capacidade para 1 $\mathrm{kg}$, no grau de torração médio. A temperatura inicial do termômetro acoplado ao torrador foi de $180^{\circ} \mathrm{C}$. A seguir, os grãos foram colocados no interior do cilindro, ocorrendo uma queda já esperada de aproximadamente $25^{\circ} \mathrm{C}$, devido à diferença de temperatura no interior do mesmo e a massa de grãos. O equilíbrio térmico foi alcançado após alguns minutos, ocorrendo uma lenta elevação da temperatura neste período, comum em processos de torração. Ao final de $10 \mathrm{~min}$ foi alcançada a tonalidade de cor desejada e as amostras foram vertidas no compartimento de resfriamento. A tonalidade da cor final dos grãos foi determinada de forma visual e instrumental (Chomameter-2 Reflectance, Minolta, Osaka, Japan). Em seguida, os grãos torrados foram moídos (moinho elétrico Pinhalense, ML-1, Brasil) em granulometria fina (20 mesh), empacotados em embalagens de polietileno/ alumínio, selados e armazenados a $-20^{\circ} \mathrm{C}$ até o uso.

Os grãos verdes foram moídos em granulometria fina em moinho refrigerado a $4{ }^{\circ} \mathrm{C}$ (Tecnal, modelo TE 631/2, Brasil) com auxílio de nitrogênio líquido. 


\section{Análise de cor}

A cor do café torrado e moído foi analisada usando-se um colorímetro (Chomameter-2 Reflectance, Minolta, Osaka, Japan) acoplado a um processador de dados (OP-300). O instrumento foi calibrado em uma placa de porcelana branca antes de cada leitura, conforme instrução do próprio fabricante. A cor foi expressa em parâmetros da escala desenvolvida pela Commission Internationale de Eclairage (CIE) L*, a*, b*. A coordenada L* representa quão clara ou escura é a amostra, com valores entre 0 (totalmente preto) e 100 (totalmente branco).

\section{Preparo da bebida}

A bebida do café foi preparada de acordo com o método de Nicoli e colaboradores, com modificações. ${ }^{12}$ Dez gramas de café em pó (verde e torrado) foram colocados em filtro de papel Whatman $\mathrm{n}$. 3 e, em seguida, foram vertidos $100 \mathrm{~mL}$ de água destilada, a $90^{\circ} \mathrm{C}$, sobre o pó contido no filtro. Todos os experimentos foram realizados com bebida preparada no momento do uso.

\section{Determinação do teor de compostos fenólicos totais}

A concentração de fenólicos totais das bebidas foi determinada pelo método de Folin-Ciocalteu. ${ }^{13}$ Amostras de $0,1 \mathrm{~mL}$ da bebida foram misturadas com $0,5 \mathrm{~mL}$ de reagente Folin-Ciocalteu diluído em água (1:10). Depois de $8 \mathrm{~min}$, foram adicionados $0,4 \mathrm{~mL}$ de solução de carbonato de sódio a $4 \%(\mathrm{~m} / \mathrm{v})$ e os tubos foram mantidos no escuro à temperatura ambiente por $2 \mathrm{~h}$. Decorrido esse tempo, a absorvância foi determinada em espectrofotômetro Shimadzu, UV-1601, Japão, a $740 \mathrm{~nm}$. A concentração de fenólicos foi calculada utilizando-se ácido tânico como padrão.

\section{Determinação dos teores de cafeína e ácido clorogênico}

Para determinação de cafeína e ácido clorogênico (ACG) foram utilizados procedimentos de extração com água quente segundo Vitorino e colaboradores, com diluição de $0,5 \mathrm{~g} / 100 \mathrm{~mL}$ de água destilada e análise por cromatografia líquida de alta eficiência (CLAE). ${ }^{14}$ Para tanto, utilizou-se um cromatógrafo da marca Shimadzu, modelo M10AVP, Japão, com coluna de fase reversa C-18 Shimadzu (100 mm de comprimento x 0.3 mm D.I., Japão). O sistema encontrava-se acoplado a um detector espectrofotométrico UV/visível Shimadzu, modelo SPD-10 ${ }^{\mathrm{A}}$, conectado por uma interface (CBM-101) a um microcomputador para processamento de dados. As condições de análise utilizadas foram fluxo de $1 \mathrm{~mL} / \mathrm{min}$; fase móvel: metanol, água e ácido acético (20:80:1); temperatura ambiente; comprimento de onda 272 $\mathrm{nm}$. A quantificação dos compostos foi obtida por comparação da área do pico do componente na amostra com a área do pico referente ao padrão externo de cafeína e do ácido 5-cafeoilquínico (Sigma,USA).

\section{Atividade sequestrante de radicais livres DPPH}

A atividade sequestrante de radicais DPPH (1,1-diphenyl-1,2picrylhydrazyl) foi determinada de acordo com o método de Yen e colaboradores, com modificações ${ }^{15}$ Cada amostra foi diluída em etanol a 0,$0125 ; 0,025 ; 0,05$ e $0,1 \mathrm{~g} \mathrm{dL}^{-1}$. Em $4 \mathrm{~mL}$ da amostra foi adicionado $1 \mathrm{~mL}$ de DPPH. (0,5 mmol.L $\left.{ }^{-1}\right)$ igualmente diluído em etanol. A mistura foi acondicionada em tubo de ensaio âmbar e agitada. Decorridos $30 \mathrm{~min}$, foi realizada a leitura a $517 \mathrm{~nm}$. A diminuição na absorvância indica atividade sequestrante de radicais livres. Os testes foram realizados em triplicata. A atividade sequestrante de radicais livres foi expressa em porcentagem por comparação ao controle,
BHT, nas mesmas diluições das amostras de café, segundo a equação:

Atividade sequestrante de DPPH $(\%)=100-\left[\left(\frac{A c-A t}{A c}\right) \times 100\right]$

onde, Ac é absorvância controle, que não foi incubada com o café e At a absorvância teste (amostras).

\section{Avaliação do poder redutor}

A avaliação do poder redutor foi realizada de acordo com Yildirim e colaboradores. ${ }^{16}$ Alíquotas de $0,01 \mathrm{~mL}$ da bebida do café, na concentração final de 200 ppm, foram diluídas em $1 \mathrm{~mL}$ de etanol absoluto e transferidas para tubo de ensaio contendo $2,5 \mathrm{~mL}$ de tampão fosfato $0,2 \mathrm{M} \mathrm{pH}$ 6,6 e 2,5 mL de ferricianeto de potássio a $1 \%(\mathrm{~m} / \mathrm{v})$. A mistura foi incubada em banho-maria a $45{ }^{\circ} \mathrm{C}$ por 20 min. Alíquotas de $2,5 \mathrm{~mL}$ de ácido tricloroacético a $10 \%(\mathrm{~m} / \mathrm{v})$ foram adicionadas ao tubo de ensaio, com posterior agitação. Alíquotas de 2,5 $\mathrm{mL}$ da mistura foram transferidas para outro tubo de ensaio, no qual foram adicionados 2,5 $\mathrm{mL}$ de água destilada e $0,5 \mathrm{~mL}$ de $\mathrm{FeCl}_{3}$ a $0,1 \%(\mathrm{~m} / \mathrm{v})$, com posterior agitação. A leitura da absorvância foi realizada a $700 \mathrm{~nm}$ (Espectrofotômetro Shimadzu, UV-1601, Japão). A atividade redutora da bebida foi expressa como porcentagem de inibição em comparação ao BHT, usado como padrão.

\section{Avaliação da atividade quelante de íons $\mathrm{Fe}^{2+}$}

A atividade quelante de íons $\mathrm{Fe}^{2+}$ foi realizada de acordo com a metodologia descrita por Tang e colaboradores, com modificações. ${ }^{17}$ Uma alíquota de $1 \mathrm{~mL}$ das amostras foi transferida para tubos de ensaio âmbar de $25 \mathrm{~mL}$. A esta alíquota foram adicionados $3,7 \mathrm{~mL}$ de água deionizada; 0,1 $\mathrm{mL}$ de $\mathrm{FeSO}_{4} 2 \mathrm{mM} \mathrm{e} \mathrm{0,2} \mathrm{mL}$ de ferrozina $5 \mathrm{mM}$ [3-(2-piridil)-5,6bis-(4-ácido fenil sulfônico) -1,2,4-triazina]. O padrão neste teste foi feito substituindo $1 \mathrm{~mL}$ da amostra por água deionizada. A mistura foi agitada e, após $20 \mathrm{~min}$, foi feita a leitura a $562 \mathrm{~nm}$ acertando o aparelho com o branco (neste caso substitui a amostra por EDTA 2\%). A redução na absorvância indica atividade quelante de metais.

$\mathrm{AQ}(\%)=100-\left[\left(\frac{A p-A t}{A p}\right) \times 100\right]$

onde, AQ é atividade quelante de metais, Ap é absorvância do padrão e At é absorvância teste (amostras).

\section{Análise estatística}

Os resultados apresentados neste estudo correspondem à média de três repetições \pm desvio padrão da média. A análise estatística foi realizada por meio de análise de variância e as diferenças significativas entre as médias foram determinadas pelo teste de Tukey, ao nível de $5 \%$ de probabilidade $(\mathrm{P}<0,05)$.

\section{RESULTADOS E DISCUSSÃO}

\section{Análise de cor}

Os resultados encontrados permitiram verificar que não houve diferença nos valores de $\mathrm{L}^{*} \mathrm{a}^{*} \mathrm{~b}^{*}$ e $\mathrm{c}^{*}$ entre os padrões de bebida analisados e que a luminosidade (L) obtida foi a mesma (integral: 20,17 descafeinado: 20,02a). A luminosidade $(\mathrm{L})$ relaciona-se ao grau de escurecimento do café, variando de 0 a 100 e com correlação significativa inversa entre os seus valores e o grau de torração, ${ }^{16}$ demonstrando que foi obtido o mesmo grau de torração nas duas amostras. 


\section{Compostos fenólicos totais}

Determinou-se o teor de compostos fenólicos totais dos diferentes extratos de café obtidos. Os valores percentuais médios das determinações dos compostos fenólicos dos cafés verdes e dos cafés torrados são apresentados na Tabela 1.

Tabela 1. Conteúdo de polifenois (g eq. ac. tânico/100 g) de dois tipos de bebida do café submetido a dois tipos de processamento

\begin{tabular}{lcc}
\hline \multirow{2}{*}{ Tipo de Bebida } & \multicolumn{2}{c}{ Processamento } \\
& Verde & Torrado \\
\hline Integral & $5,30 \pm 0,06 \mathrm{aA}$ & $4,73 \pm 0,09 \mathrm{aB}$ \\
Descaf & $5,05 \pm 0,06 \mathrm{bA}$ & $4,13 \pm 0,07 \mathrm{bB}$ \\
\hline
\end{tabular}

Médias seguidas por letras minúsculas diferentes dentro de cada coluna e médias seguidas por letras maiúsculas diferentes dentro de cada linha diferem entre si $(\mathrm{p}<0,05)$, pelo teste de Tukey.

O processo de descafeinação ocasionou a perda de $5 \%$ dos compostos fenólicos totais. O café integral ao passar pelo processo de descafeinação perde, além da cafeína, parte dos seus compostos fenólicos, o que explica a diferença nos teores entre as amostras verdes. O processo de torração ocasionou perdas de até $18 \%$ dos polifenois inicialmente presentes na amostra verde. Estes resultados indicam que o processo de torração foi fator relevante para diminuição dos teores dos polifenois. ${ }^{7}$ A análise desses compostos é de grande importância quando se pretende verificar atividade antioxidante de uma amostra, pois os mesmos desempenham um papel importante na neutralização ou sequestro de radicais livres e quelação de metais de transição. ${ }^{18}$

\section{Cafeína e ácido clorogênico}

A determinação de cafeína e ACG por CLAE (Figura 1) foi feita com base na curva padrão de calibração de cada substância, usando-se padrões analíticos para cada composto. Os tempos de retenção identificados foram os seguintes: ACG ( 9 min) e cafeína ( 10 min). Ao contrário da cafeína, o ácido clorogênico é bastante sensível à torração. ${ }^{19}$

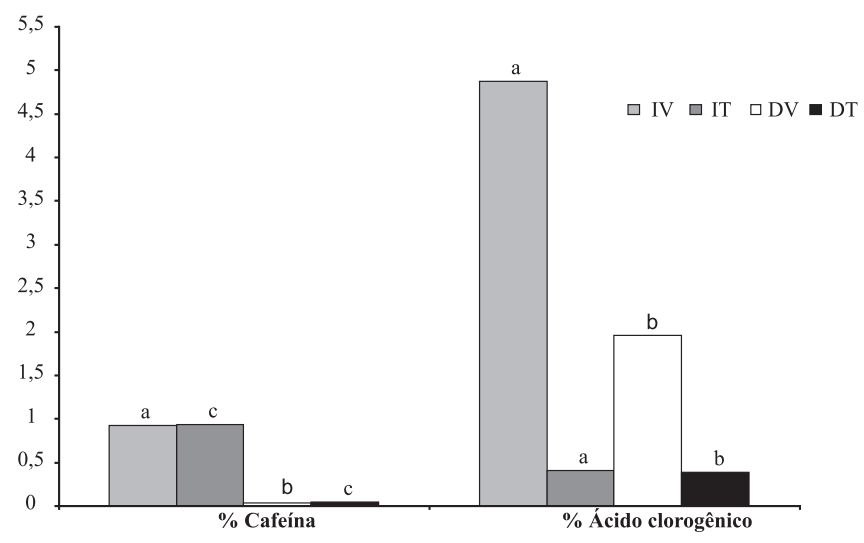

Figura 1. Teores médios de cafeína e ácido clorogênico em cafés integral verde (IV), descafeinado verde (DV), integral torrado (IT) e descafeinado torrado (DT). Médias seguidas por letras diferentes nas colunas diferem entre si $(p<0,05)$, pelo teste de Tukey

O teor de ACG foi reduzido com o processo de descafeinação, com perdas de $60 \%$ na amostra descafeinada verde (Figura 1). Essa perda pode ter ocorrido, em parte, devido à complexação entre cafeína e ACG descrita na literatura, ${ }^{20}$ mas tendo em vista o baixo teor de ACG complexado à cafeína no café, outras causas devem ser consi- deradas. A diminuição deve ter ocorrido, em sua maior parte, devido à isomerização do ACG quando em contato com altas temperaturas para evaporação do solvente e secagem dos grãos durante o processo de descafeinação com diclorometano.?

A torração levou a perdas de $92 \%$ nos níveis de ACG, fato que está de acordo com os valores descritos por Fujioka e colaboradores, que analisaram cafés comercias integral e descafeinado e verificaram após a torração uma perda de até $93 \%$. $^{21}$ Durante a torração dos grãos, parte dos ácidos clorogênicos é incorporada na composição de outras substâncias que são formadas durante esse processo e que estão relacionadas à cor e ao sabor do café. ${ }^{22}$

A permanência residual de maiores teores de ACG após o processamento do café pode ser benéfica, tendo em vista a atividade antioxidante dessa classe de compostos. ${ }^{23}$

Os resultados mostraram a estabilidade da cafeína após a torração (Figura 1), embora pequenas perdas de cafeína possam ocorrer por sublimação a $178^{\circ} \mathrm{C} .^{7}$

O teor de cafeína encontrado na amostra integral verde é similar ao valor encontrado por Perrone e colaboradores, ${ }^{24}$ ambos em concordância com os valores relatados na literatura para grãos verdes de café arábica - de 0,9 a $1,3 \mathrm{~g} \%{ }^{25} \mathrm{O}$ teor de cafeína da amostra verde descafeinada $(0,03 \%)$ encontra-se de acordo com a legislação brasileira, que define um patamar de $0,1 \%$ de cafeína em café descafeinado. ${ }^{26}$

Considerando que tanto o ácido clorogênico como a cafeína vêm sendo indicados como compostos potencialmente antioxidantes, ${ }^{12,27,28}$ os resultados apresentados sugerem menor atividade antioxidante nas amostras descafeinadas.

\section{Atividade sequestrante de radicais DPPH}

Na Tabela 2 estão representados os resultados da atividade sequestrante de radicais DPPH das bebidas de café. O butil-hidróxi-tolueno (BHT) foi utilizado como padrão.

Tabela 2. Atividade sequestrante do radical DPPH (\%) das bebidas de café integral torrado (IT), integral verde (IV), descafeinado torrado (DT), descafeinado verde (DV) e do padrão BHT em quatro concentrações

\begin{tabular}{lcccc}
\hline Tipo de & \multicolumn{4}{c}{ Concentração $\left(\mathrm{g} \mathrm{dL}^{-1}\right)$} \\
Bebida & 0,0125 & 0,025 & 0,05 & 0,1 \\
\hline IT & $55,86 \pm 0,94 \mathrm{~b}$ & $64,77 \pm 0,51 \mathrm{~b}$ & $68,47 \pm 0,59 \mathrm{~b}$ & $70,20 \pm 0,76 \mathrm{~b}$ \\
IV & $50,49 \pm 1,01 \mathrm{~d}$ & $53,91 \pm 1,05 \mathrm{c}$ & $54,40 \pm 1,03 \mathrm{~d}$ & $55,51 \pm 0,85 \mathrm{~d}$ \\
DT & $52,99 \pm 0,91 \mathrm{c}$ & $64,04 \pm 0,83 \mathrm{~b}$ & $64,66 \pm 0,92 \mathrm{c}$ & $68,46 \pm 0,84 \mathrm{c}$ \\
DV & $47,50 \pm 0,51 \mathrm{e}$ & $49,89 \pm 0,53 \mathrm{~d}$ & $50,92 \pm 0,77 \mathrm{e}$ & $54,80 \pm 0,70 \mathrm{~d}$ \\
BHT & $57,61 \pm 0,58 \mathrm{a}$ & $74,67 \pm 0,69 \mathrm{a}$ & $88,69 \pm 0,32 \mathrm{a}$ & $94,80 \pm 1,02 \mathrm{a}$ \\
\hline
\end{tabular}

Médias seguidas por letras minúsculas diferentes dentro de cada coluna diferem entre si $(\mathrm{p}<0,05)$, pelo teste de Tukey.

O padrão BHT apresentou a maior atividade sequestrante de DPPH em todas as concentrações. Todas as amostras apresentaram atividade sequestrante de radicais DPPH dose-dependente, isto é, um aumento da proteção com aumento da dose (Tabela 2). O mecanismo de redução de radicais livres DPPH envolve a doação de hidrogênio. Neste sistema tanto a estrutura planar como espacial do composto antioxidante é importante. Baseado em dados da literatura é possível inferir que a potente atividade antioxidante de extratos polares é dada pela presença de substâncias com hidroxilas. ${ }^{29}$

O processo de descafeinação e a torração influenciaram na atividade antioxidante das bebidas de café $(\mathrm{p}<0,05)$. As bebidas preparadas a partir dos cafés descafeinados apresentaram menor atividade, demonstrando que substâncias sequestradoras de radicais 
livres foram, em parte, perdidas durante o processo de descafeinação. A atividade sequestrante de radicais livres dos cafés verdes foi menor que a apresentada por Naidu e colaboradores, que encontrou valores próximos a $80 \%$ em cafés verdes da espécie arábica. ${ }^{30}$

A atividade antioxidante das bebidas foi potencializada com a torração. O mesmo comportamento foi verificado em grãos de café torrados que apresentaram maior atividade antioxidante quando comparados a grãos verdes, que por sua vez continham maiores concentrações de antioxidantes polifenólicos, ${ }^{7,31}$ sugerindo assim que outros compostos poderiam ser responsáveis pela atividade antioxidante em grãos de café submetidos à torração.

Os resultados deste trabalho indicam que as bebidas de café torrado, independente da descafeinação, apresentam uma maior capacidade de doar hidrogênio, pois apresentaram as maiores porcentagens sequestrante de DPPH, atingindo 70,2\% com a amostra integral.

\section{Poder redutor}

O teste de avaliação do poder redutor baseia-se na redução do íon ferricianeto a ferrocianeto que, na presença do íon férrico (proveniente do $\mathrm{FeCl}_{3}$ ), forma o azul da Prússia. ${ }^{4} \mathrm{~A}$ redução é dada tomando-se o BHT como $100 \%$. As médias dos valores obtidos na análise do poder redutor das bebidas de café amostradas estão apresentadas na Tabela 3 .

Tabela 3. Poder redutor (\%) de dois tipos de bebida do café submetido a dois tipos de processamento

\begin{tabular}{lcc}
\hline \multirow{2}{*}{ Tipo de Bebida } & \multicolumn{2}{c}{ Processamento } \\
& Verde & Torrado \\
\hline Integral & $53,48 \pm 1,00 \mathrm{aB}$ & $76,75 \pm 0,97 \mathrm{aA}$ \\
Descaf. & $48,10 \pm 1,09 \mathrm{bB}$ & $58,99 \pm 1,00 \mathrm{bA}$ \\
\hline
\end{tabular}

Médias seguidas por letras minúsculas diferentes dentro de cada coluna e médias seguidas por letras maiúsculas diferentes dentro de cada linha diferem entre si $(\mathrm{p}<0,05)$, pelo teste de Tukey.

O processo de descafeinação diminuiu a capacidade redutora das bebidas em $10 \%$. Neste caso é muito provável que essa diferença se deva ao menor teor de polifenois e de cafeína na amostra verde descafeinada. Já a torração do café integral aumentou em $43 \%$ o poder redutor da bebida; esse efeito não foi tão pronunciado na amostra descafeinada que após a torração aumentou em $23 \%$ seu poder redutor $(\mathrm{p}<0,05)$ (Tabela 3 ).

Nicoli e colaboradores, ao estudarem o efeito do processamento e armazenamento de alimentos (tomates e café), relataram que, apesar da concentração dos antioxidantes naturais ter sido significantemente reduzida em consequência dos tratamentos térmicos, as propriedades antioxidantes dos alimentos estavam preservadas ou mesmo aumentadas pelo desenvolvimento de novos produtos com atividade antioxidante. ${ }^{12}$ Daglia e colaboradores também verificaram um aumento no poder redutor com a torração em cafés arábica. ${ }^{31}$

Os resultados obtidos indicam novamente a presença de outras substâncias com propriedades antioxidantes formadas durante o processo de torração, como as melanoidinas formadas através da reação de Maillard. ${ }^{32}$

\section{Poder quelante de $\mathrm{Fe}^{2+}$}

$\mathrm{Na}$ avaliação da atividade quelante, a ferrozina, um reagente cromogênico, torna a solução rósea de acordo com a quantidade de ferro disponível em solução. Assim, quanto menor a quelação de íons pela amostra, maior o número de íons disponíveis para reação com a ferrozina e maior será a absorvância. Os resultados do poder quelante das bebidas de café verde e torrado, integral e descafeinado estão apresentados na Tabela 4.
Tabela 4. Poder quelante de $\mathrm{Fe}^{2+}(\%)$ das bebidas de café integral torrado (IT), integral verde (IV), descafeinado torrado (DT) e descafeinado verde (DV), em três concentrações

\begin{tabular}{lccc}
\hline Tipo de Bebida & \multicolumn{3}{c}{ Concentração $\left(\mathrm{g} \mathrm{dL}^{-1}\right)$} \\
& 0,15 & 0,2 & 0,4 \\
\hline IT & $5,78 \pm 0,15 \mathrm{c}$ & $16,77 \pm 1,07 \mathrm{c}$ & $38,28 \pm 1,07 \mathrm{c}$ \\
IV & $36,58 \pm 0,63 \mathrm{a}$ & $51,04 \pm 0,22 \mathrm{a}$ & $72,73 \pm 0,33 \mathrm{a}$ \\
DT & $5,13 \pm 1,09 \mathrm{c}$ & $15,67 \pm 1,01 \mathrm{c}$ & $28,42 \pm 0,99 \mathrm{~d}$ \\
DV & $25,68 \pm 0,31 \mathrm{~b}$ & $44,12 \pm 0,92 \mathrm{~b}$ & $63,27 \pm 1,00 \mathrm{~b}$ \\
\hline
\end{tabular}

Médias seguidas por letras minúsculas diferentes dentro de cada coluna diferem entre si $(\mathrm{p}<0,05)$, pelo teste de Tukey.

As amostras avaliadas apresentaram poder quelante de $\mathrm{Fe}^{2+}$ dosedependente. Assim como nos testes anteriores houve influência da descafeinação e da torração no poder quelante das amostras $(p<0,05)$. A porcentagem de atividade quelante de $\mathrm{Fe}^{2+}$ das amostras de café verde superou as amostras de café torrado (Tabela 4). Os resultados apresentados corroboram com Santos e colaboradores, que encontraram uma maior atividade quelante nas amostras de café verde. ${ }^{4}$

A diminuição de compostos com atividade quelante, como polifenois e cafeína, durante o processo de descafeinação pode ter levado à diminuição dessa atividade nas amostras descafeinadas. Os cafés torrados, independente do processo de descafeinação, mostraram o mesmo poder quelante de metais, com exceção na concentração de $0,4 \mathrm{~g} \mathrm{dL}^{-1}$, na qual o café torrado integral superou o café torrado descafeinado.

Nesta análise, os cafés verdes demonstraram maior atividade antioxidante que os torrados, resultado diferente do obtido na análise da atividade sequestrante de radicais livres e poder redutor. Uma maior concentração de polifenois neste caso é favorável, pois um dos seus mecanismos de ação antioxidante de especial relevância é a capacidade de se ligar a metais tais como íons ferro e cobre, impedindo ou minimizando a participação destes em reações de Fenton. ${ }^{33}$ Esse resultado permite sugerir a utilização do extrato de café verde em alimentos ao invés de agentes quelantes sintéticos com o objetivo de prevenir a deterioração dos mesmos e de certa forma melhorar seu valor nutritivo.

Nota-se que a atividade antioxidante das amostras analisadas variou conforme a metodologia utilizada, o que demonstra a importância da realização de mais de uma análise para que se tenha uma maior confiabilidade nos resultados.

\section{CONCLUSÃO}

A descafeinação diminui a atividade antioxidante in vitro da bebida do café, já o processo de torração potencializa a atividade sequestrante de radicais livres e o poder redutor das bebidas. As bebidas de café analisadas, independente do processo de torração e de descafeinação, apresentam atividade antioxidante, podendo contribuir para a prevenção ou redução do desenvolvimento de patologias associadas ao estresse oxidativo.

\section{AGRADECIMENTOS}

À Coordenação de Aperfeiçoamento de Pessoal de Nível Superior - Capes, pela concessão da bolsa de estudos.

\section{REFERÊNCIAS}

1. Kumazawa, K.; Masuda, H.; J. Agric. Food Chem. 2003, 51, 2674.

2. Halsted, C. H.; Am. J. Clin. Nutr. 2003, 77, 1001.

3. Roginsky, V.; Lissi, E. A.; Food Chem. 2005, 92, 235. 
4. Santos, M. H.; Batista, B. L.; Duarte, S. M. S.; Lemos, B.; Quim. Nova 2007, 30, 604

5. Zheng, W.; Wang, S. Y.; J. Agric. Food Chem. 2001, 49, 5165.

6. Silvarolla, M. B.; Mazzafera, P.; Fazuoli, L. C.; Nature 2004, 429, 826.

7. Toci, A.; Farah, A.; Trugo, L. C.; Quim. Nova 2006, 29, 965.

8. Nkondjock, A.; Cancer Lett. 2009, 2, 121.

9. Monteiro, M. C.; Trugo, L. C.; Quim. Nova 2005, 28, 637.

10. Cavin, C.; Holzhaeuser, D.; Scharf, G.; Constable, A.; Huber, W. W.; Schilter, B.; Food Chem. Toxicol. 2002, 40, 1155.

11. Morais, S. A. L.; Aquino, F. J. T.; Nascimento, P. M.; Nascimento, E. A.; Chang, R.; Quim. Nova 2009, 32, 327.

12. Nicoli, M. C.; Anese, M.; Manzocco, L.; Lerice, C. R.; Lebensmittel Wissenschaft und - Technologie. 1997, 30, 292

13. Woisk, R. G.; Salatino, A.; J. Apicult. Res. 1998, 37, 99.

14. Vitorino, M. D.; França, A. S.; Oliveira, L. S.; Borges, M. L. A.; Revista Brasileira de Armazenamento 2001, 26, 17.

15. Yen, W. J.; Chang, L. W.; Duh, P. D.; Food Sci. Technol. 2005, 38, 193.

16. Yildirim, A.; Oktay, M.; Bülaloúlu, V.; Turk. J. Med. Sci. 2001, 31, 23.

17. Tang, S. Z.; Kerry, J. P.; Sheehan, D.; Buckley, D. J.; Food Chem. 2002, 76,45 .

18. Basile, A.; Ferrara, L.; Del Pozzo, M.; Mele, G.; Sorbo, S.; Bassi, P.; Montesano, D.; J. Ethnopharmacol. 2005, 102, 32.

19. Nogueira, M.; Trugo, L. C.; Ciênc. Tecnol. Aliment. 2003, 23, 296.
20. Waldhauser, S. S. M.; Baumann, T. W.; Phytochemistry 1996, 42, 985.

21. Fujioka, K; Shibamoto, T.; Food Chem. 2008, 106, 217.

22. Farah, A., Paulis, T., Trugo, L. C., Martin, P. R.; J. Agric. Food Chem. 2005, 53, 1505 .

23. Stadler, R. H.; Turesky, R. J.; Muller, O.; Markovic, J.; Leongmorgenthaler, P. M.; Mutat. Res. 1994, 308, 177.

24. Perrone, D.; Donangelo, C. M; Farah, A.; Food Chem. 2008, 110, 1030.

25. Clifford, M. N.; Proc. Biochem. 1975, 10, 20.

26. http://www.anvisa.gov.br/legis/portarias/377_99.htm, acessada em Novembro 2009.

27. Lee, C.; Clin. Chim. Acta 2000, 295, 141.

28. Duarte, S. M. S.; Abreu, C. M. P.; Menezes, H. C.; Santos, M. H.; Gouvêa, C. M. C. P.; Ciênc. Tecnol. Aliment. 2005, 25, 387.

29. Mensor, L. L.; Menezes, F. S.; Leitão, G. G.; Reis, A. S.; Santos, T. C.; Coube, C. S.; Phyt. Res. 2001, 15, 27.

30. Naidu, M. M.; Sulochanamma, G.; Sampathu, S. R.; Srinivas, P.; Food Chem. 2007, 107, 377.

31. Daglia, M.; Papetti, A.; Gregotti,C.; Bertè, F.; Gazzani, G.; J. Agric. Food Chem. 2000, 48, 1449.

32. López-Galilea, I.; Andueza, S.; Di Leonardo, I.; Peña, M. P.; Cid, C.; Food Chem. 2006, 94, 75.

33. Lopes, G. K. B.; Schulman, H. M.; Hermes-Lima, M.; Biochim. Biophys. Acta, Gen. Subj. 1999, 1472, 142. 